\title{
Neurological Manifestations of Systemic Lupus Erytematosus
}

\author{
Hernández Ramos, F. J. ${ }^{\text {; }}$ Hernández Chamorro, F. J. ${ }^{\text {; }}$ Medina Rodríguez, M. ${ }^{1}$; Palomino García, A. ${ }^{1}$; \\ Jiménez Hernández, M.D. ${ }^{1}$
}

${ }^{1}$ Neurosystemics Unit; Clinic Unit of Neurology and Neurophysiology, University Hospital Virgen del Rocío, Seville Spain

${ }^{2}$ School of Medicine, University of Seville (Spain)

*Corresponding author: Hernández Ramos, Francisco José; currohernandez@gmail.com;

francisco.hernandez.ramos.sspa@juntadeandalucia.es.

Received: 21 November 2020;

Accepted: 30 November 2020;

Published: 05 December 2020

\begin{abstract}
s
Systemic lupus erythematosus (SLE) is the prototype of autoimmune disease with multisystemic damage capacity. Its diagnosis is based on clinical and immune criteria, which have been recently updated by EULAR/ACR, making positive antinuclear antibodies (ANA) a necessary part of the diagnosis criteria. Those criteria are responsible for the decrease in the neurological manifestations, in comparison with the former criteria.

Eighty seven LES patient's retrospective hospital sample. Sociodemographic variables, autoimmune family history, years of evolution, diagnosis, antibodies, neurological clinic, image tests, electroencephalography and cerebrospinal fluid, treatment and obtained score according to EULAR/ACR criteria are being analysed.

Seventy patients and seventeen with other diagnosis are obtained, where $84.3 \%$ are women with an average age of 44.64 years, no autoimmune family history in $54.70 \%$ of the cases, an average of 15.3 years of evolution, $100 \%$ of ANA and $75 \%$ antiDNA positives. Headache, seizures, strokes and cognitive impairment are the most common neurological manifestations. $78.6 \%$ of them lack an image test, where steroids are the most used immunosuppressor (58.24\%), followed by hydroxychloroquine (48.6\%).

The frequency of the discussed neurological manifestations is similar to the one present in current literature, having cognitive decline a low prevalence. Our sample's neurological manifestations lack of statistical significance for SLE diagnosis, being anti-DNA antibodies are crucial for it. We suggest that a prospective study with less years of evolution, widening the neurological manifestations and having anti-DNA antibodies as entry criterion, can increase statistical significance.
\end{abstract}

Keywords: "Lupus"; "neurology and lupus "; "ANA and anti.DNA"; "lupus diagnostic criteria"; "EULAR / ARC criteria".

\section{Introduction}

Systemic lupus erythematosus (SLE) ${ }^{[1]}$ is the autoimmune disease by excellence, whose mechanism to produce the pathology is mediated by cells, autoantibodies or immunocomplexes. It presents a low prevalence rate in Spain, 9/10,000 inhabitants, with multisystemic damage and reaching the nervous system in $60 \%$ of the cases, according to population studies with a high variability. It is more frequent in women (90\%), and there is a $95 \%$ chance of survival after 5 years, $78 \%$ after 20 years: causing a decrease in the patients' quality of life.

It's physiopathology is complex. Upon a genetic predisposition, the intervention of a series of environmental factors induce an alteration in the immune system, which is responsible for the neurologic clinic at the end (Figure 1) ${ }^{[2-6]}$.

In the nervous system's pathogeny, ${ }^{[7]}$ hematoencephalic barrier's alteration, choroid plexus and antiphospholipid antibodies mediated vascular damage intervene. They determinate an increase in the permeability of immunoglobulins, lymphocytes, complement system and vascular and neurological damage mediator molecules. The neurological manifestations have been divided into focal and dim, affecting the central and peripherical nervous system (Figure 2) ${ }^{[8-11]}$. The most frequent ones are cognitive alterations, cephalea, seizures, stroke and psychosis ${ }^{[12]}$.

It is important to point out the clinical variability: from asymptomatic patients with positive antibodies- the most minor manifestation- to the most fatal clinic. They represent both opposite ends of the disease's clinical variability.

Regarding the treatment, a differentiation must be made between the one used for treating the outbreaks and the immunosuppressor treatment, which seeks mid to large term clinical stability. The former consists mostly of steroids and sometimes intravenous cyclophosphamide. The latter uses immunosuppressors as a base, as well as several biological 
treatments, such as belimumab and rituximab ${ }^{[13]}$. Antiphospholipid syndrome's treatment, often associated with SLE, needs antithrombotic treatment.

Until September 2019, 2012 diagnosis criteria were still valid. The new EULAR/ACR criteria (Figure 3) determine that in order to affirm that a patient has lupus, they must have ANA positive $>1 / 80$, as well as an above 10 punctuation with at least one clinical criterion ${ }^{[14,15]}$.
The neurological criteria have suffered a great change. Seizures, psychosis and delirium are 5,3 and 2 points respectively, eliminating the current ones in 2012. These criteria maintain a $93.4 \%$ specificity and increase sensitivity up to $96.1 \%$. However, they omit clinic that can be part of the disease's manifestation and they should include a higher level of antibodies ${ }^{[16]}$.

\section{$\underline{\text { Figure } 01}$}

- $\quad$ GENETIC PREDISPOSITION ( $\mathrm{HLA} \mathrm{DR}_{2}, \mathrm{DR}_{3}$ AND B8)

- $\quad$ LOCI (>80), STAT $_{4}(\mathrm{CD} 4+$ PROLIFERATION STIMULANT THROUGH IL-12R $\rightarrow$ GAMMA $\rightarrow$ ACTIVATION CD4+)

- $\quad$ CONGENITAL COMPLEMENT DEFICITS (C1Q, C2, C4) $\rightarrow$ INHIBIT CD8 MITOCHONDRIAL METABOLISM.

- $\quad$ GALECTIN 3 DEFICIT IN GERM CENTERS $\rightarrow$ INCREASE GAMMA-INF $\rightarrow$ PROLIFERATION OF LYMPHOCYTES AND AUTOANTIBODIES.

- IL21'S ROLE AS PLASMOCYTE DIFFERENTIATION REGULATOR AND AUTOANTIBODY FORMATION.

- $\quad$ BAFF IS ACTIVATOR OF LYMPHOCYTES B. REGULATES THE RECOGNITION OF ANTIGENS

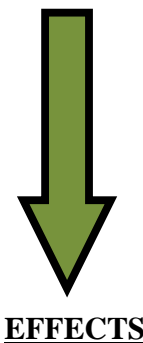

1. ADAPTIVE AND SPECIFIC IMMUNE HYPERACTIVATION.

2. FAILURE IN THE REMOVAL OF ANTIGENS FROM THE CIRCULATORY TORRENT.

3. LOWER TOLERANCE TO THE RECOGNITION OF APOPTOTIC CELLS.

4. FAILURE IN NEGATIVE REGULATION OF CD4 AND CD8.

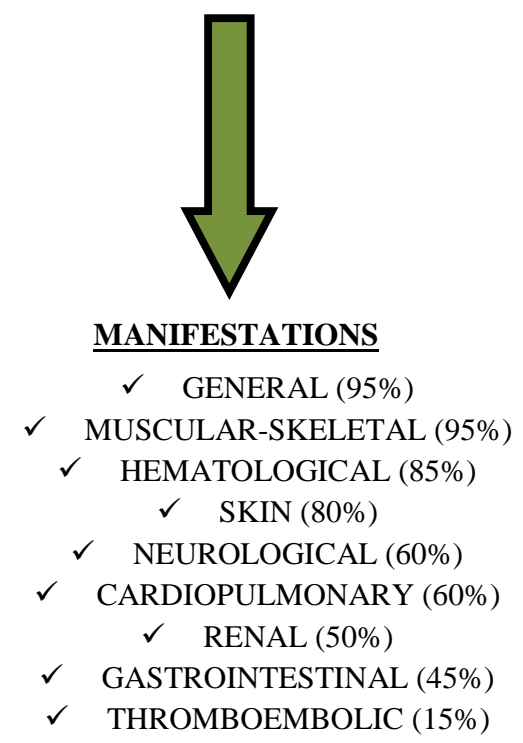

Figure 02

\begin{tabular}{|l|l|}
\hline CENTRAL & PERIPHERAL \\
\hline ASEPTIC MENINGITIS & GUILLAIN BARRÉ SYNDROME \\
\hline STROKE & AUTONOMIC NEUROPATHY \\
\hline DEMYELINATING SYNDROMES & MONONEUROPATHY \\
\hline HEADACHE & MIASTENIFORM SYNDROME \\
\hline MOVEMENT DISORDERS & CRANIAL NEUROPATHY \\
\hline SEIZURES & PLEXOPATHY \\
\hline ACUTE CONFUSIONAL SYNDROME & POLYNEUROPATHY \\
\hline ANXIETY DISORDER & \\
\hline COGNITIVE IMPAIRMENT & \\
\hline MOOD DISORDERS & \\
\hline PSYCHOSIS & \\
\hline
\end{tabular}


Figure 03

\section{Entry criterion}

Antinuclear antibodies (ANA) at a titer of $\geq 1: 80$ on HEp-2 cells or an equivalent positive test (ever)

$\downarrow$

If absent, do not classify as SLE

If present, apply additive criteria

\begin{tabular}{|c|c|c|c|}
\hline \multicolumn{4}{|c|}{$\begin{array}{l}\text { Additive criteria } \\
\text { rion if there is a more like } \\
\text { criterion on at least one } \\
\text { uires at least one clinical } \\
\text { ria need not occur simult } \\
\text { ighest weighted criterion }\end{array}$} \\
\hline Clinical domains and criteria & Weight & Immunology domains and criteria & Weight \\
\hline \multicolumn{2}{|l|}{ Constitutional } & \multirow{3}{*}{\multicolumn{2}{|c|}{$\begin{array}{l}\text { Antiphospholipid antibodies } \\
\text { Anti-cardiolipin antibodies OR } \\
\text { Anti- } \beta 2 \text { GP1 antibodies OR }\end{array}$}} \\
\hline Fever & 2 & & \\
\hline \multicolumn{2}{|l|}{ Hematologic } & & \\
\hline Leukopenia & 3 & Lupus anticoagulant & 2 \\
\hline Thrombocytopenia & 4 & \multicolumn{2}{|l|}{ Complement proteins } \\
\hline Autoimmune hemolysis & 4 & Low C3 OR low C4 & 3 \\
\hline \multicolumn{2}{|l|}{ Neuropsychiatric } & Low C3 AND low C4 & 4 \\
\hline Delirium & 2 & \multirow{3}{*}{\multicolumn{2}{|c|}{$\begin{array}{l}\text { SLE-specific antibodies } \\
\text { Anti-dsDNA antibody* OR } \\
\text { Anti-Smith antibody }\end{array}$}} \\
\hline Psychosis & 3 & & \\
\hline Seizure & 5 & & 6 \\
\hline \multicolumn{4}{|l|}{ Mucocutaneous } \\
\hline Non-scarring alopecia & 2 & & \\
\hline Oral ulcers & 2 & & \\
\hline Subacute cutaneous OR discoid lupus & 4 & & \\
\hline Acute cutaneous lupus & 6 & & \\
\hline \multicolumn{4}{|l|}{ Serosal } \\
\hline Pleural or pericardial effusion & 5 & & \\
\hline Acute pericarditis & 6 & & \\
\hline \multicolumn{4}{|l|}{ Musculoskeletal } \\
\hline Joint involvement & 6 & & \\
\hline \multicolumn{4}{|l|}{ Renal } \\
\hline Proteinuria $>0.5 \mathrm{~g} / 24 \mathrm{~h}$ & 4 & & \\
\hline Renal biopsy Class II or V lupus nephritis & 8 & & \\
\hline Renal biopsy Class III or IV lupus nephritis & 10 & & \\
\hline \multicolumn{4}{|c|}{ Total score: } \\
\hline
\end{tabular}

Classify as Systemic Lupus Erythematosus with a score of $\mathbf{1 0}$ or more if entry criterion fulfilled.

\section{Material and Methods}

Our work's design has been done in the following way:

Data bases bibliographic search (PubMed and Academic Google) of last 10 year's SLE's diagnosis criteria, etiopathogenesis, clinic and antibodies related articles.

- SLE neurological manifestations' search in Neurology and Internal Medicine manuals.

- $\quad$ Retrospective and hospital-based experimental study. A data base has been created, gathering information from three different sources: a 50 lupus and anti-DNA positive patient's hospital sample; a 27 patients with lupus and its neurological manifestations' hospital sample- followed in the Neurosystemics Unit; and a 113 anti-DNA positive patients' hospital sample from the Immunology department, where only 10 of them have been selected, due to temporary reasons and to the fact that they had similar characteristics to the previous sources.

As a result, we gather an 87 patients' sample. A clinical DIRAYA history analysis was carried out, mainly in neurology, internal 
medicine and nephrology. The data were gathered between $1 / 1 / 2018$ and 1/9/2019. The capture-recapture method was used in order to avoid duplicities. The data were divided into the following 11 categories:

- Sociodemographic; age and sex.

- Autoimmune family history.

- Disease's years of evolution.

- Diagnosis.

- $\quad$ Antibodies (ANA, anti-DNA, ENA and antiphospholipid antibodies).

- Neurological manifestations.

- $\quad$ Image tests and type of present injuries.

- Electroencephalography and cerebrospinal fluid.

- Anti-lupus treatment.

- Non-neurological SLE related clinic.

- Punctuation according to 2019 EULAR/ACR criteria.

The data are transformed into binary code for its SPSS analysis. An analysis by Chi-square statistics, for relating the qualitative variables among them.

Analysing our sample, we consider the following objectives:

\section{Primary:}

- Determine the neurological manifestations' prevalence of SLE diagnosed patients.

- Determine the patient's frequency, according to sex, age, autoimmune family history, evolution time, diagnosis' tests and anti-lupus treatment.

- Determine the different measured antibodies' effectivity in diagnosis.

\section{Secondary}

- Critical analysis on EULAR/ACR criteria, regarding neurological manifestations.

Our study has received the Andalusian Ethical Committee for investigation's approval (Code 29996).

\section{Results}

The following results from our sample are obtained:

From the 87 cases, there are 70 patients with SLE diagnosis, while the other 17 have an alternative one: 3 mixed connective tissue disease patients, 2 myotonic dystrophy patients, 1 with primary antiphospholipid syndrome, 6 non-defined collagenosis, 1 with Sjogren's syndrome, 1 scleroderma, 1 patient with cholestasis, 1 with isolated CNS vasculitis and 1 with cutaneous lupus.

- $\quad$ There are 11 males and 59 females (15.7\% and 84.3\%)

- Age range follows a normal distribution, with an average age of 44.46 and a $14.053 \mathrm{DE}$ (IC at 95\% (41.29-47.99)).

- The average years of evolution follow a normal distribution, 15.31 years and 7.795 DE (IC at $95 \%$ (13.37-17.22)).

- There is no autoimmune family history in $54.30 \%$ of the patients, being SLE the most frequent one (15.7\%) (Table 1).

- Antibodies are positive in 67 patients (95.7\%). Both patients with negative results have close to no data in their clinical history. There is one from MUFACE, who has almost no tracking. Therefore, it could be assumed that they all have SLE diagnosis, meaning that the entire patients are ANA positive. Regarding the different antibodies' effectivity in diagnosis, the Chi-square method is used, in order to see the relation between both qualitative variables and to obtain statistical significance, as well as authenticity (Table 2). ANA, anti-DNA, antihistone and antiphospholipid antibodies show statistical significance for diagnosis.

- Regarding the neurology clinic (Table 1), headache, seizures, stroke and cognitive decline are the manifestations that prevail. General manifestations are more common than the localised ones, being less frequent in the CNS. None of the analysed clinical manifestations have statistical significance for the SLE diagnosis study.

- In the complementary tests, the $78 \%$ of the patients lack brain CT/IMR. Only 15 patients have had a CT done, showing 4 lacunar strokes and 1 with white matter injury. Other 23 patients have had a IMR done, showing 5 lacunar strokes and 7 with white matter injury. 10 patients have had an electroencephalography done, where all of them showed a normal result. 4 patients have had a lumbar puncture done, where only one of them showed an anormal result: lymphocytic pleocytosis.

- About the anti-lupus treatment used, 18 patients did not take it $(26.08 \%)$. The steroid-based immunosuppressor treatment is used in the $58.24 \%$, and the most used nonsteroid-based one is hydroxychloroquine (48.6\%) (Table 1).

Table 01

\begin{tabular}{|c|c|c|c|c|c|}
\hline & & Frequency & $\%$ & + & $\begin{array}{l}\text { Rpl Reason For } \\
\text { Positive Likelihood }\end{array}$ \\
\hline & No & 38 & 54.30 & & \\
\hline \multirow[t]{2}{*}{ 1. Family History } & Yes & 20 & 28.60 & & \\
\hline & Not Included & 12 & 17.20 & & \\
\hline \multicolumn{6}{|l|}{ 2. $\quad$ Clinic } \\
\hline & Diffuse & 20 & 48.52 & & \\
\hline \multirow[t]{5}{*}{ A) } & Focal & 8 & 20 & & \\
\hline & Peripheral & 4 & 8.57 & & \\
\hline & Multiple & 9 & 22.51 & & \\
\hline & Headache & & 25.70 & & \\
\hline & Seizures & & 11.43 & & \\
\hline
\end{tabular}




\begin{tabular}{|l|l|l|l|l|l|}
\hline B) & Stroke & & 8.57 & & \\
\hline & Cognitive Impairment & & 8.57 & & \\
\hline & Others & & 18.57 & & \\
\hline & & & & & \\
\hline & Ana & & 100 & $X$ & 5.13 \\
\hline $3 . \quad$ Antibody & Anti-Dna & & 75 & $X$ & 11.72 \\
\hline & Ena & & 78.5 & $X$ & 4.878 \\
\hline & Histone & & 48.7 & $X$ & 6.47 \\
\hline & Anti-Phospholipid & & 32.9 & $X$ & 10.13 \\
\hline & & & & & \\
\hline & Steroid & 12 & 17.4 & & \\
\hline & Steroid + & 28 & 40.58 & & \\
\hline & Non-Steroid Inmunosuppressant & 10 & 14.50 & & \\
\hline
\end{tabular}

Steroid $+=$ Steroid and Other Inmunosuppressor.

\section{Discussion}

In our sample, the age and sex distribution are corelated with the population data. It is more frequent in women. In $54 \%$ of the patients, there is no family history of autoimmune disease and when there is, most of the time it is lupus. The general neurological manifestations are more frequent than the ones in the peripherical nervous system and the localised ones. The low frequency in which cognitive decline takes place surprises us. That could be related to the population's average age (44.64 years). Since it is relatively low, there is no real need for neuropsychological tests, therefore there are no diagnosis done.

Regarding the different antibodies' positiveness and their relationship with SLE's diagnosis, we obtain that the ANA have statistical significance. However, due to the fact that it can also happen in other pathologies and that $5-10 \%$ of the population can have them too, its positiveness cannot be used as part of the SLE diagnosis' criteria- since they are high sensitive, but low specificity antibodies. ENA, antihistones and antiphospholipid antibodies also have statistical significance. Anti-DNA are the most significant ones for SLE diagnosis.

The current neurological clinic criteria for diagnosisseizures, psychosis and delirium (5,3 and 2 points, respectively)have a great importance in those ANA positive and scarce symptomatology patients. Nevertheless, in our sample they lack statistical significance for our diagnosis. Probably because of their average years' evolution (15.33 years) and the rare frequency of those symptoms in our sample.

The conclusion that we can reach after finishing our sample's analysis are:

- Our sample's SLE patient's population presents a distribution by sex, age and neurological manifestations' frequency similar to the one present in the current literature.

- There is a low prevalence of cognitive decline, probably related to its infradiagnosis.

- EULAR/ACR criteria for neurological manifestations lack statistical significance. Which could be related to the average evolution years (15.33) and the rare prevalence of seizures, psychosis and delirium in our sample.

- Antibodies have a statistical significance for diagnosis, specially anti-DNA. Those antibodies used as diagnosis criteria instead of ANA could bring a higher sensitivity and specificity for the current criteria.
- The current EULAR/ACR criteria could widen the neurological manifestations demanded for lupus' diagnosis.

- It would be recommended to carry out a prospective study in order to value the lupus related neurological manifestations.

\section{Limitations}

Retrospective study. Hospital study. Possible selection bias in the Neurosystemics consult's sample (27 patients). Low percentage of patients which have had a brain CT/IMR/LP/electroencephalography.

\section{Appreciation}

To Loli Chamorro Jiménez and Paula Hernández Chamorro for their help when it came to write this article.

\section{Ethics approval and consent to participate}

Our study has received the Andalusian Ethical Committee for investigation's approval (Code 29996).

\section{List of abbreviations}

SLE: systemic lupus eritematosus.

EULAR: European League Against Rheumatism.

ANA: Antinuclear antibody.

Anti-DNA: Anti deoxyribonucleid acid antibody.

ENA: Nucleus extractable antybody.

CNS: Central nervous system.

SD: Standard deviation.

MUFACE: General Mutual Funding of Civil Servants of State.

CT: Computed tomography.

IRM: Nuclear magnetic resonance.

\section{Conflict of interest}

The autor(s) declare(s) that there is no conflict of interest regarding the publication of this paper. 


\section{Funding Statement}

Not applicable.

\section{Author's contributions}

Hernández Chamorro FJ, Medina Rodríguez M, Palomino García A and Jiménez Hernández MD , have helped in the final preparation of this paper and was a mayor contribution in writing the manuscript. All authors read and approved the final manuscript.

\section{Acknowledgments}

To Loli Chamorro JIménez and Paula Hernández Chamorro for their help in the figures and table and traducction of this paper.

\section{Bibliography}

[1] Breva; Hannahs; Hahn. Lupus eritematoso generalizado. En: Dan L. Longo, Dennis L. Kasper, J. Larry Jameson, Anthony S. Fauci, Stephen L. Hauser, Joseph Loscalzo. Principios de Medicina Interna. Ed 18. Nueva york: McGraw Hill Interamericana editores S.L; 2012 p.207583.

[2] Delunardo F, Soldati D, Bellisario V, et al. Anti-GAPDH Autoantibodies as a Pathogenic Determinant and Potential Biomarker of Neuropsychiatric Diseases. 2016;68(11):2708-16.

[3] Pollard KM, Cauvi DM, Meroni PL. Antiglutamate receptor Antibodies and cognitive impairment in Primary Antiphospholipid syndrome and systemic Lupus erythematosus. 2016;7(February):5-10.

[4] Yang Y, Yuan C, Shen S, et al. Autoantibodies to NR2A Peptide of the Glutamate / NMDA Receptor in Patients with Seizure Disorders in Neuropsychiatric Systemic Lupus Erythematosus. 2017;2017.

[5] Gelb S, Stock AD, Anzi S, et al. Mechanisms of Neuropsychiatric Lupus: The Relative Roles of the Blood-CSF versus Blood-Brain Barrier. 2019;34-44.
[6] Qu C, Zhang J, Zhang X, et al. Value of combined detection of anti - nuclear antibody, anti - double stranded DNA antibody and C3, C4 complements in the clinical diagnosis of systemic lupus erythematosus. 2019;1390-4.

[7] Correale J. Compromiso del sistema nervioso en las enfermedades reumatológicas. En: Correale J; Villa A; Garcea O. Neuroinmunología clínica. Buenos Aires: Panamericana; 2011. 327-44.

[8] Hanly JG, Li Q, Su L, et al. Psychosis in Systemic Lupus Erythematosus: Results From an International Inception Cohort Study. 2019;71(2):281-9.

[9] Hanly JG, Li Q, Su L, et al. Cerebrovascular Events in Systemic Lupus Erythematosus. 2019;70(10):1478-87.

[10] Id FC, Pirone C, Mina C, et al. Pragmatic language dysfunction in systemic lupus erythematosus patients: Results from a single center Italian study. 2019;1-11.

[11] Kumar S, Ramiro S, Voorde LJB De, et al. Are serum autoantibodies associated with brain changes in systemic lupus erythematosus? MRI data from the Leiden NP-SLE cohort. 2019;(November 2018):94-103.

[12] Kampylafka EI, Alexopoulos H, Kosmidis ML, et al. (2013) Incidence and Prevalence of Major Central Nervous System Involvement in Systemic Lupus Erythematosus: A 3-Year Prospective Study of 370 Patients. PLOS ONE 8(2): e55843. https://doi.org/10.1371/journal.pone.0055843

[13] Marenco JL, Ferna A. Experiencia con rituximab en el tratamiento de pacientes con lupus . La base de datos LESIMAB. 2010;6:28-33.

[14] Aringer M, Costenbader K, Daikh D, et al. 2019 European League Against Rheumatism / American College of Rheumatology Classification Criteria for Systemic Lupus Erythematosus. 2019;71(9):1400-12.

[15] Otón T, Instituto S, Musculoesquelética DS, Madrid I. Nuevos criterios de clasificación de lupus eritematoso sistémico. 2019;4-7.

[16] Zucchi D, Elefante E, Calabresi E, et al. Review One year in review 2019: systemic lupus erythematosus. 2019;(6):715-22. 